\title{
Understanding the Dynamics of Language Centers in Non-School Setting
}

\author{
Katrina Ninfa M. Topacio \\ Research Cluster on Culture, Education and Social Issues \\ Rm 211, Thomas Aquinas Research Complex \\ University of Santo Tomas \\ España, Manila 1015, Philippines
}

Trunk Line: (63-2) 406-1611 Telefax: (63-2) 731-3535

E-mail: katrinamtopacio27@gmail.com

Received: January 19, 2015 Accepted: February 10, 2015 Published: February 12, 2015

doi:10.5296/ijele.v3i1.7090 URL: http://dx.doi.org/10.5296/ijele.v3i1.7090

\begin{abstract}
Language centers as a form of outside schooling are gaining local and international reputation for their contribution to English language training. However, despite of them being widespread, only very few and limited researches have been conducted about them. This paper, hence, aimed to explore the phenomenon behind language centers by identifying their purpose, programs and practices that made them effective contributors to English language education despite their deregulated status. To collect data, the study used semi-structured interview and class observation conducted among five language centers situated in a non-school setting. Results of the interview showed that although language centers are deregulated educational institutions, they follow a structure similar to a regular school, but may differ when it comes to flexibility of curriculum, diagnostic procedure, classroom management and student evaluation process. It was also observed that while language centers are primarily profit-driven, they abide to learning philosophies or institutional objectives that are transformed and applied to their teaching approaches and style. Other data from interview were classified according to instructional management style, administrative roles and policies and human resource management. Furthermore, it has also been observed how language centers play an important role in the economy and society.
\end{abstract}

Keywords: language centers, foreign language education, global English, language and society 


\section{Introduction}

Outside schooling, after-school programs or what has been termed as shadow education is not a new activity in the country and even in the global scenario. Its acceptability worldwide can be attributed to its capacity to compensate for the limitations of formal schooling and support achievement of students aimed within formal education (Baker et al., 2001). Lately, there has been an increasing concern to learn English globally in the modern society. According to Richards (2006), "The ever growing need for good communication skills in English has created a huge demand for English teaching around the world." (p.1) Because of this pressing matter, language tutorial centers or schools have now become a widespread phenomenon.

The spread of language centers can be attributed to the status of English as an international language in both global and local sense. While there is a huge number of native speakers using English, according to Mckay (2000), more bilingual speakers of English are to be observed in the coming decades. English has received its status as a language of wider communication because it is spoken among individuals from different countries and at the same time spoken among individuals within the same country as well for a variety of purposes, usually for cross-cultural communication and other more restricted usage like accessing and sharing information. Moreover, English reached this worldwide status because of the dominance it has established in trade and commerce as well as in cultural and literary traditions. This is a view shared by Kachru (1992) when he even mentioned that even anti-Western governments and anti-English movements are already using the language to express their views and ideas to the world and even some parents from these nations willingly provide their children with English education.

It assumed that it is because of the same reason why students from different parts of the globe are arriving in the country to provide themselves with quality English education. "After all, English has the power, and they (parents) want their children to be equipped with this powerful linguistic tool" (Kachru, 1992, p.355). However, with more and more non-native speakers speaking and learning to speak the language at present, Mckay and Kachru also contend on re-examining the way English is being taught considering learners from different backgrounds and varieties of English used.

In the Philippines alone, language education is flourishing that it has even been referred to as 'the world's budget English teacher' (McGeowen, 2012). A rapid increase in foreign students coming to the Philippines to learn English has been observed over the years. According to BBC website, this occurrence can be attributed not only to Filipinos' capacity to speak English fluently and efficiently but more importantly because quality English education in the Philippines is more affordable than getting it from native English speaking counterparts. Aside from attracting fellow Asians from Korea, Japan and other neighboring countries, the Philippines has recently been attracting also students from the Middle East, South America and Europe like Iran, Libya, Brazil and Russia.

Moreover, the reputation of the Philippines being an English speaking nation has further been highlighted by a recent study showing the country as the world's best when in comes to Business English. According to Global English Website, Philippines scored the highest and 
was the only one categorized as high level of proficiency which means Filipinos has the ability to take active roles in business discussion and perform relatively complex tasks. The article further explained that such is a result of the Filipinos' 'seriousness of pursuing language education and English language research.'

With a plethora of skills and the appropriate cost, the country indeed has the potential to become a world's English teacher therefore giving rise to many language centers and language schools in the country. However, while language centers are already widespread, very few researchers have been conducted about such phenomenon. Furthermore, while it has been discussed that the Philippines' potential to teach English both locally and globally has been recognized, very few is known about what made language centers effective in supporting this phenomenon. What about LC structure, curriculum content, and instruction made students patronize them?

In the process of making this research the following questions and issues needed to be addressed. First, it important to determine their purpose and goals they have established in order to carry out their tasks effectively. What administrators, owners, teachers or even students think about the purpose of their language center will also reflect the important role that they play in the present society and as contributors to education and even the industry. Second, this research aims to know the learning programs language centers are offering that they think will help them achieve their purpose. Since they are offering courses that are given outside a regular school environment, it is also important to establish, although they may mimic school-like approaches and activities, if there are certain differences in the design, approaches and teaching methodologies. And lastly, this research also aims to know how as an organized structure, LCs are able to perform their tasks effectively by identifying their management styles and administrative procedures.

\section{Methods}

Since the topic on language centers is a phenomenon not yet discussed in literature, it is reasonable to follow the principles of phenomenological research in order to find answers to questions in this study. Data collected are purely qualitative as provided by semi-structured interviews, classroom observations and company documents.

Interview was conducted among five language centers in Metro Manila. Criteria for choosing language centers as participants in this study are based on the following: (1) should be operating for three years or more, (2) should offer at least English language courses, and (3) should be accredited at least by TESDA (Technical Education and Skills Development Authority) or any other outside government agency.

Language centers were initially contacted through telephone, and formal letters asking for permission to interview administrators or managers and conduct classroom observations were forwarded. Before the actual interview, participants were asked to sign consent form confirming their willingness to participate in the research.

Interview questions are divided into three parts Purpose, Programs and Practices in Instruction and Administration. All interviews were audio-recorded and transcribed by an 
independent transcriber. After transcription, the researcher analyzed data through coding to identify emerging and important themes and concepts that are related to the phenomenon.

\section{Results and Discussion}

It is most important to know that all language centers involved in the study have the three fundamental aspects for them to carry out tasks effectively. The table below shows a summary of these aspects characterizing the dynamics of language centers as organizations.

Table 1. Aspects characterizing dynamics of language centers

\begin{tabular}{|c|c|c|}
\hline PURPOSE & What to HARNESS & $\begin{array}{l}\text { Refers to the reason/s for } \\
\text { which language centers exist } \\
\text { which may be manifested in } \\
\text { their philosophy, mission and } \\
\text { objectives as a learning } \\
\text { institution. These reasons } \\
\text { may be internally or } \\
\text { externally initiated. }\end{array}$ \\
\hline $\begin{array}{ll}\text { PROGRAMS } & \text { and } \\
\text { FEATURES } & \end{array}$ & What to HIGHLIGHT & $\begin{array}{l}\text { Programs refer to curriculum } \\
\text { and courses offered within } \\
\text { language centers. This aspect } \\
\text { also focuses on the highlights } \\
\text { or features of language center } \\
\text { programs (as outside school } \\
\text { programs) which made them } \\
\text { different from regular school } \\
\text { programs. }\end{array}$ \\
\hline PRACTICES & How to HANDLE & $\begin{array}{l}\text { This refers to observable } \\
\text { processes that language } \\
\text { centers have been using to } \\
\text { achieve their institution's } \\
\text { purpose and manage systems } \\
\text { within it. These include } \\
\text { instructional management, } \\
\text { human resource } \\
\text { management, policies and } \\
\text { marketing. }\end{array}$ \\
\hline
\end{tabular}

\subsection{What to Harness: Purpose and Goals of LCs}

Data collected from interviews, documents and even the LC's online account revealed that these LC's purposes can be divided into three categories: perceived, initial purpose and incidental purpose. Initial and perceived purposes are internally initiated, which refer to ones determined by the institution itself and which they are aware of, while incidental purpose is 
externally-initiated, which refer to incidental roles that they play in the larger community or society.

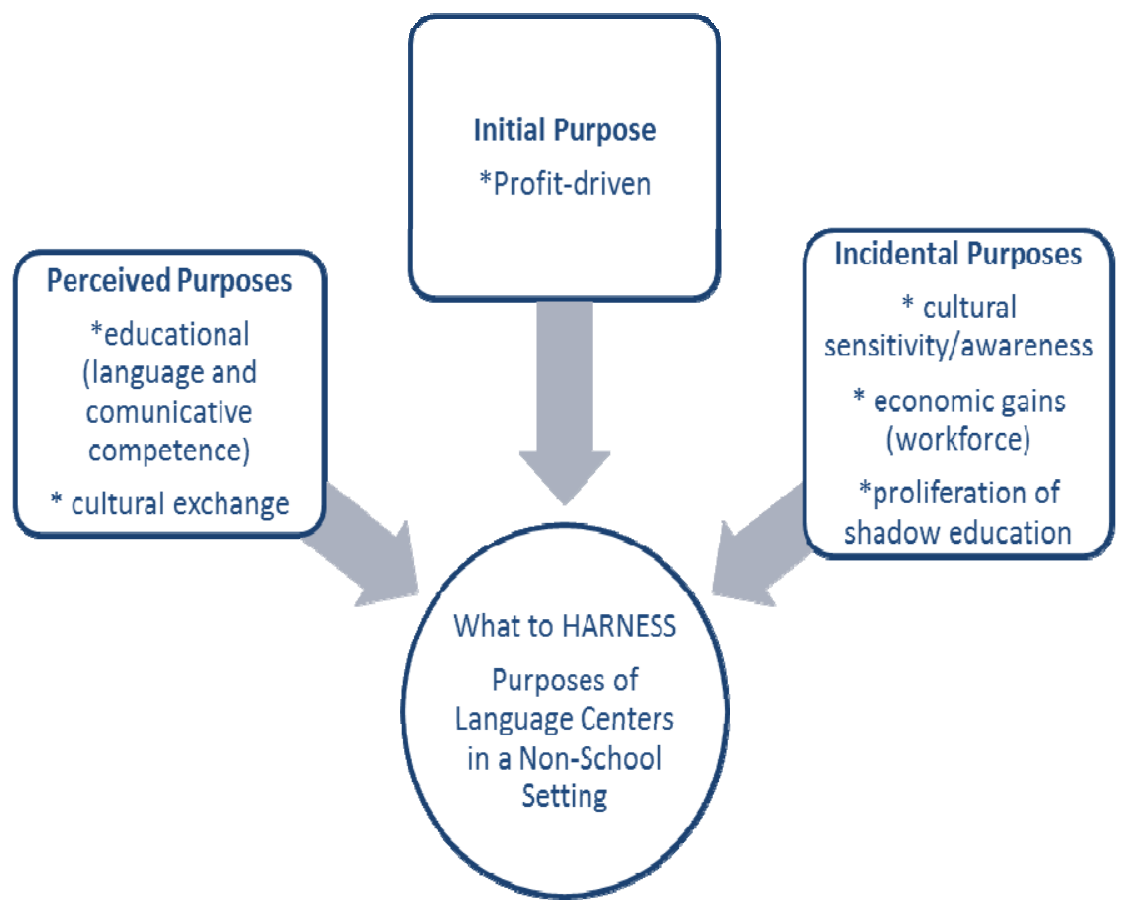

Diagram 1. Purposes of Non-School Based Language Centers

The following are examples of interview quotations showing how language centers describe their purpose as an institution/ organization:

Table 2. Perceived Purpose - Promoting Communication Skills through Teaching Languages

"The purpose of the institute is to make everyone a world speaker. That's why we're teaching different languages... but we are currently training leaders as well.” NSLBC2

"Our philosophy as a learning institution is to inspire, challenge, and empower each student to continuously progress and to divine the infinite world of learning and endless possibilities. "NSLBC3

"Well, the purpose of (NSLBC4) is to provide alternatives to Filipinos by learning another language... philosophy is to focus on fostering commitment, building the culture and promoting effective communication and mutual understanding. "NSLBC4

"They do come here in the Philippines and study in a language center, they get to speak with teachers, with other students using English as a medium - so for me... language centers, especially for foreigners, are there to assist them in learning English in an English environment." NSLBC5

"...mission is to 'make language (learning) easy, fun and effective', continuously work hard to find ways to refine training courses and teaching methods. Its vision and philosophy is to inspire, challenge and empower each student to continuously progress and to divine the infinite world of learning and endless possibilities" NSLBC5

Perceived purposes are carefully and thoughtfully formulated purposes as seen in their own institutional philosophy and goals through their statement of mission, vision and/or objective. 
Statements are similar to school-based objectives when they mostly discuss the proliferation of quality education particularly in communication using English or another language. The objectives have also been formulated to highlight positive values referring to excellence, perseverance and empowerment. Perceived purposes categorized here are understood to have been carefully planned, formulated and initiated by the language centers.

However, it can also be assumed given the profit-earning nature of LCs that institutional philosophies, as printed in their marketing tools such as flyers and brochures and posted in their websites, that they are also used for promotional purposes. A well-established and expressed set of goals and objectives, mission and vision give the clients an idea of excellent organizational structure going on inside a company. This builds a feeling of trustworthiness towards the company providing services.

Table 3. Perceived Purpose - Cultural Exchange and Understanding

"(The) philosophy of (NSLBC1) is mainly ... we have this slogan - word connection, cultural understanding. Our management has this simple idea - What if we make the Philippines as a satellite of high quality education that we don't see in XXXXX? Or if not, invite people from Europe and Asia to the Philippines to become a melting pot (of cultures) through language learning." NSLBC1

"The (NSLBC4's) mission is to help people of the world learn about one another, their cultures, their language and their ideologies. We are an organization of language enthusiasts aimed to bring people closer to their goals through responsible and excellent teaching of language, prescribes to educate, inform and promote the extremes of culture..." NSLBC4

Aside from educational goals, some LCs have also mentioned about the importance of knowing other cultures through interaction with foreigners who enroll themselves in English language programs. This happens because foreigners, who come to the country, first learn about another country's cultures from first-hand resources in his learning environment and at the same time the same environment provides him the opportunity to speak about and represent his own culture in another language. Moreover, a local student or foreign student studying another language apart from his own native language is undergoing some kind of acculturation through language learning.

In some LCs, cultural awareness, understanding and exchange has been incorporated in their institutional objectives and philosophy. In some cases, respect for other cultures is also part of their institutional policies. This only shows that they (language centers) understand their important role in this cultural exchange and understanding.

Table 4. Initial Purpose - Profit-Earning Goal

"... we generate income through education, and that income goes to helping especially for them 'cause they're tied with the business community throughout the world" NSLBC1

"This school or this institute started as a non-profit organization catering to those Filipinos who wants (sic) to learn languages but as time goes by... it became a business. We now have different branches." NSLBC 2

“... Honestly... of course, language center is business... so the reason why we put it up.... (is to be) source of income. NSLBC3 
Aside from their role in the proliferation of language education, it cannot be denied that they are primarily profit-earning companies. In fact, in four of the interviews, it was mentioned that aside from educational goals, their objective is to earn profits. Profit-earning objective is classified under Initial purpose, which is primarily the reason why any other companies or businesses exist. This shows that language centers have been thriving as business in the country. Such phenomenon can be attributed to the fact that there is a big demand of language learning in the country and around the globe, and that the country has enough resources to address such demands.

Table 5. Incidental Purpose - Economic Gains

“...English is a second language here in the Philippines and I understand that most of the Filipinos have been trying to learn English since pre-school, as time goes by because of the call center industry... we have learned that it's not enough just to know English. We have to do something about the language like polish our accent. That way we can be understood everywhere... "NSLBC2

While it has been mentioned in the interviews that there is a demand on learning language to increase chances of employment among its clients, not one directly mentioned that their objective was to contribute to the workforce of the country by providing teaching jobs to Filipinos in their own language center and preparing their clients for their own employment in the future. Although, some LCs mentioned their goal 'education-to employment', it was not discussed how they are aware of their economic contributions by increasing employment potential. It is for this reason that this purpose has been categorized as incidental. Although, not directly mentioned in their institutional objectives as planned goals, such purpose clearly exists in the economic and societal level.

In answering the question about what to harness, it has been revealed that language centers are geared towards providing language education based on demands, aside from the initial goal to earn profits. However, in discussing purpose during the interviews, another emerging theme is WHY foreign clients choose the Philippines for the English language education.

The following table shows some excerpts from the interviews that give light to this topic.

Table 6. Why foreigners choose the Philippines for their Language Education

"... Some of they say it's cheaper because they come from middle-class families... so instead of spending more (in England or America), they can spend (more affordably) in the Philippines. "NSLBC1

“They would say... Filipino teachers are really patient and we have a neutral accent. "NSLBC1

"They choose the Philippines... one, because here it's not too stressful (learning English). When they go to America, it's really pure English... and they don't have that much patience teaching foreigners... students get intimidated. I think Filipinos (in comparison) are very patient. NSLBC5 
This preference for language learning in the Philippines can be seen as a positive impact to the country's economy. As discussed earlier, demand for English language education can increase employment opportunities for language instructors and at the same time contribute also to tourism economy. It can be seen from the interview quotations above that foreign students' choice is based on affordability of education including lodging and other expenses, the Philippine English intelligibility when it come to accent or sound, and positive characteristics of Filipino teachers.

\subsection{What to Highlight: Programs and Features}

Programs are essential parts of the dynamics of language centers. It is the content of the organization and what clients actually pursue. In understanding language center activity, it was also important to know what programs are being offered in these institutions, why these programs are the ones being offered, how these programs were designed to fulfill the purpose, and what features or highlights of the programs made them different from what regular schools offer.

The following table shows a summary of the programs offered in non-school based language centers in the Philippines. Column A shows programs offered in all language centers interviewed; Column B shows programs offered in some; and, Column C are special programs offered only in one LC.

Table 7. Programs Offered in Language Centers

\begin{tabular}{|c|c|c|}
\hline $\begin{array}{l}\text { A- Common-to-All } \\
\text { Programs }\end{array}$ & $\begin{array}{l}\text { B- Common-to-Some } \\
\text { Programs }\end{array}$ & C - Specialized Programs \\
\hline $\begin{array}{l}\text { English (General) } \\
\text { English as Second Language } \\
\text { Exam Preparations: IELTS } \\
\text { (International English } \\
\text { Language Testing System), } \\
\text { TOEFL (Test of English as a } \\
\text { Foreign Language) }\end{array}$ & $\begin{array}{l}\text { Business English } \\
\text { Foreign Languages: Filipino, } \\
\text { Turkey, Russian, Arab, } \\
\text { Japanese, Korean, Greek, } \\
\text { Dutch, French, Norwegian, } \\
\text { Cantonese, Mandarin, } \\
\text { Fookien } \\
\text { Academic Tutorials } \\
\text { Online ESL Courses } \\
\text { Language for Call Centers } \\
\text { Language Translation and } \\
\text { Interpretation } \\
\text { English Conversational } \\
\text { Fluency } \\
\text { Intensive Grammar Review } \\
\text { Onsite Corporate Training } \\
\text { Professional Communication }\end{array}$ & 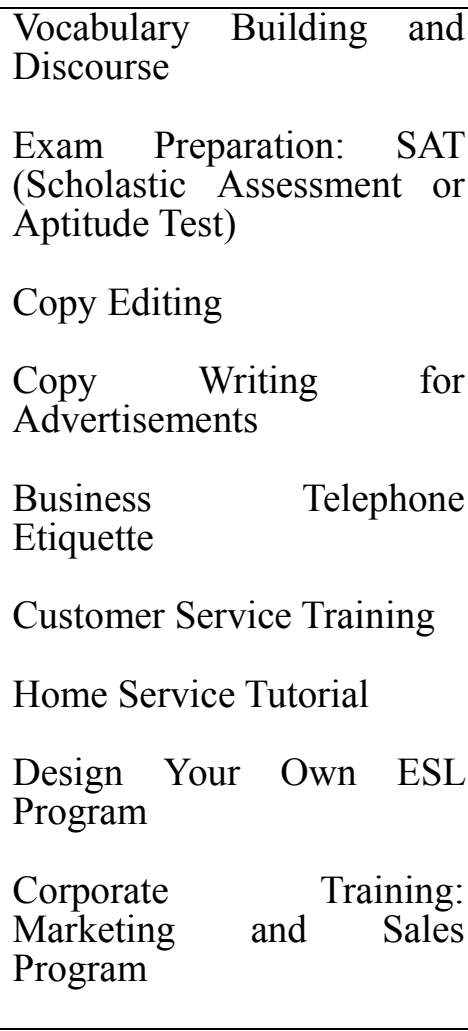 \\
\hline
\end{tabular}




\begin{tabular}{|l|l|l|}
\hline & $\begin{array}{l}\text { Training Programs } \\
\text { Leadership Programs } \\
\text { Children English } \\
\text { Winter and Summer Camps }\end{array}$ & $\begin{array}{l}\text { Industrial Relations Courses } \\
\end{array}$ \\
\hline
\end{tabular}

English as second language is common program to all language centers given the demand and plethora of resources available in the country. Foreign language programs are offered by some language centers on an irregular schedule due to its seasonal nature and limited teaching resources particularly language instructors. Specialized programs are particularly designed by the language centers to target additional skills most commonly related to business communication or communication in the workplace.

It can also be highlighted here how the programs offered are related to the purposes discussed earlier. Various language programs are offered to advance communication skills, but based on the programs' list it can also be seen that there are two tracks of development being highlighted: first is to supplement regular school activities through English academic tutorials and SAT exam preparation and summer camps, and second is to prepare clients for the workplace through corporate training programs. It can also be seen that these language centers offer programs based on demand and the resources available to them.

Other important things to note are how the programs are designed and what sellable features are highlighted. The following table shows interview quotations giving light to these matters.

Table 8. Deregulated Curriculum and Individualized Learning

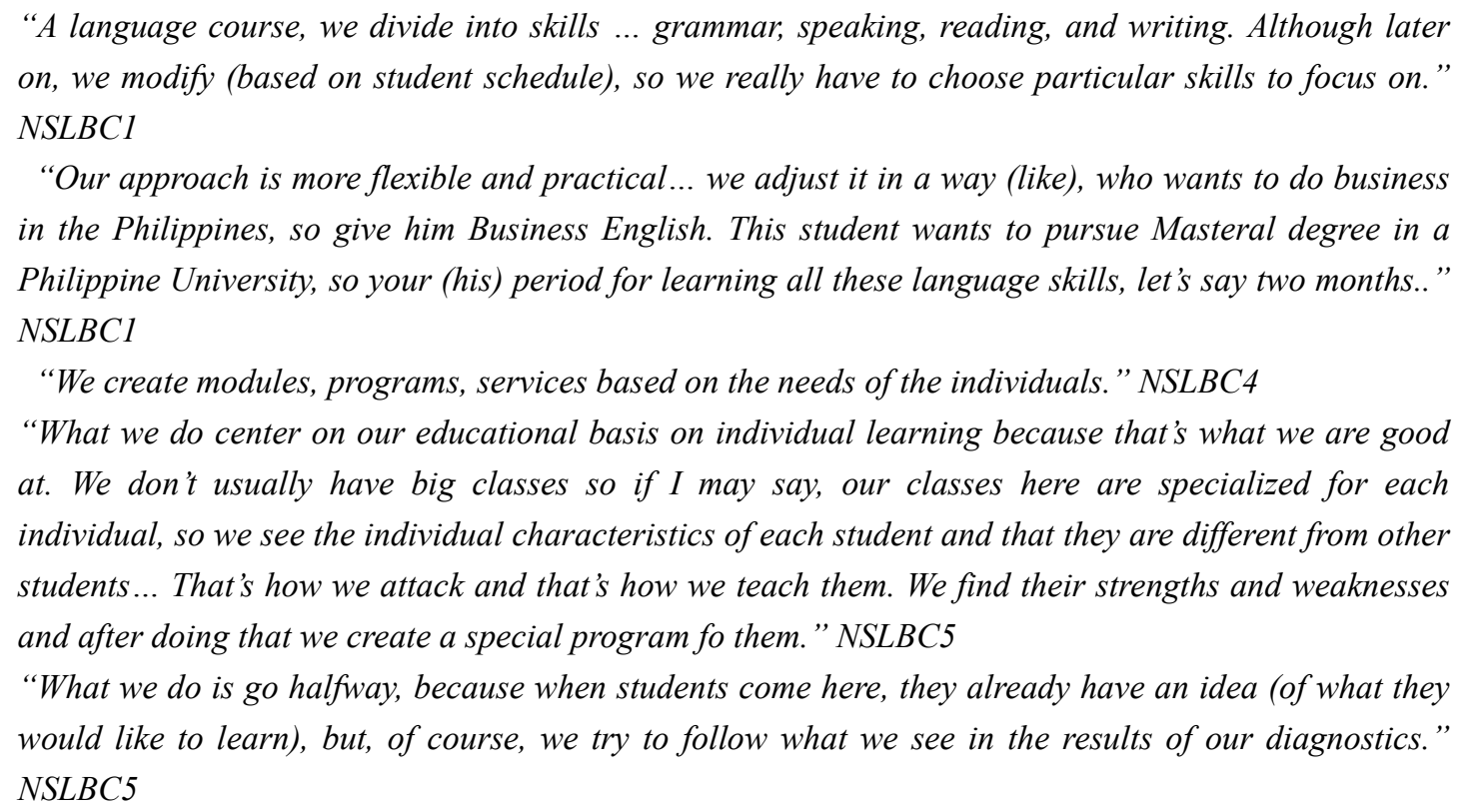

"Our approach is more flexible and practical... we adjust it in a way (like), who wants to do business in the Philippines, so give him Business English. This student wants to pursue Masteral degree in a Philippine University, so your (his) period for learning all these language skills, let's say two months.." NSLBC1

“We create modules, programs, services based on the needs of the individuals. " NSLBC4

"What we do center on our educational basis on individual learning because that's what we are good at. We don't usually have big classes so if I may say, our classes here are specialized for each individual, so we see the individual characteristics of each student and that they are different from other students... That's how we attack and that's how we teach them. We find their strengths and weaknesses and after doing that we create a special program fo them." NSLBC5

"What we do is go halfway, because when students come here, they already have an idea (of what they would like to learn), but, of course, we try to follow what we see in the results of our diagnostics." NSLBC5 
One distinctive feature of curriculum in language centers is that of flexibility that can be seen in several ways. First, the programs are flexible in terms of time offered and scheduling. One of the primary concerns of clients is time. Since foreigners stay only for a limited time in the country, they have to ensure that they get to learn all the target skills before they return to their native country or before they start another activity in the country like tertiary or graduate education or business activities. Another way this can be seen is that language centers do not prescribe a particular school year calendar unlike regular schools. Courses can start and end anytime it is most convenient to the client. Second, flexibility can be seen in the way focus skills are given emphasis according to the end goal of the student, whether it for academic purposes that he or she is learning a language or to seek employment for a certain job. Third, the programs are flexible according to the proficient level of he student. The following table shows how diagnostics are important for the program managers to determine the exact program or series of lessons appropriate for an individual.

Table 9. Importance of Diagnostics

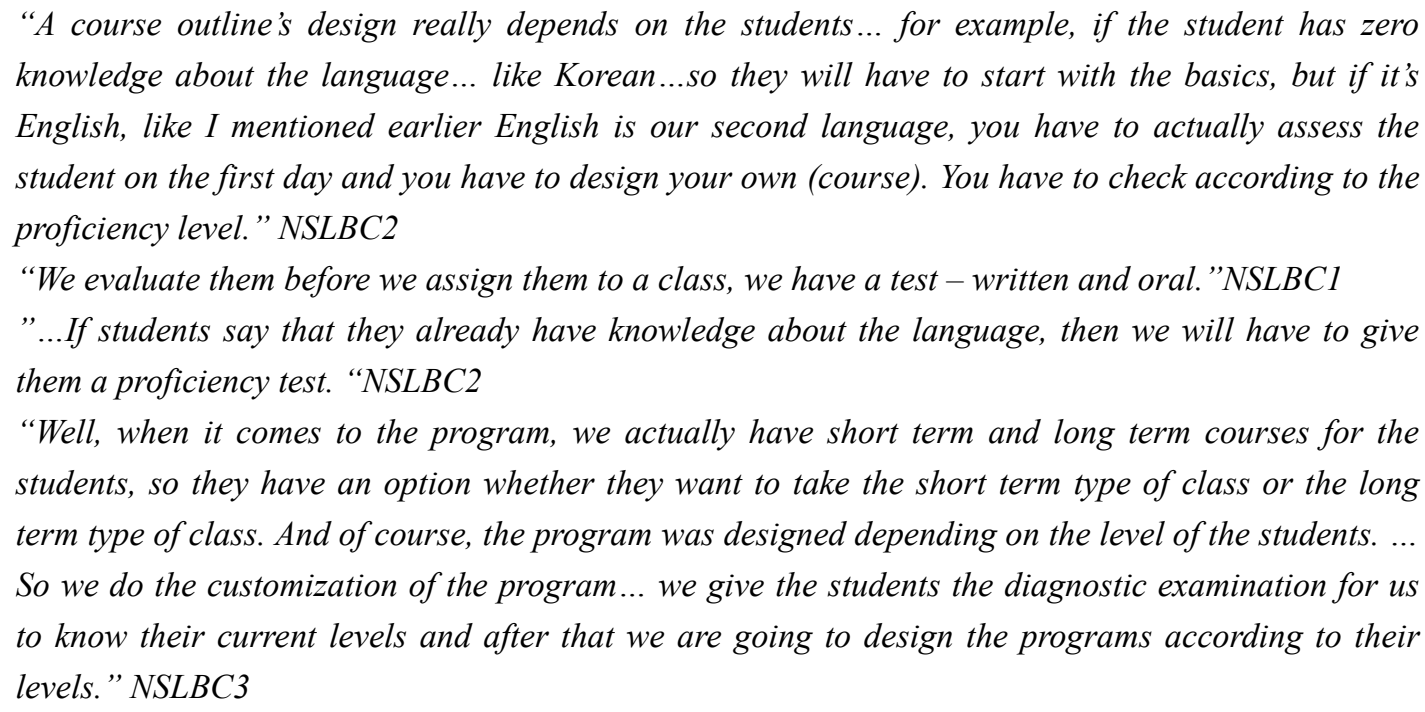

Programs have been designed according to varying levels of proficiencies. A student may not start at the bottom if found out through diagnostics that he/she have achieved already a certain proficiency. Also, the level of proficiency cannot be determined by social status, age, nationality or even educational attainment.

The ability to flex programs according to students' needs show that language center courses are deregulated, individualized and even client-centered. It can also be seen how one feature can lead to another.

Aside from the programs themselves and how they are designed, LCs believe that their teaching methodology or the implementation of the programs themselves are also different from regular school teaching methodology. The following table presents example quotations from the interviews. 
Table 10.:LC Teaching Methodology

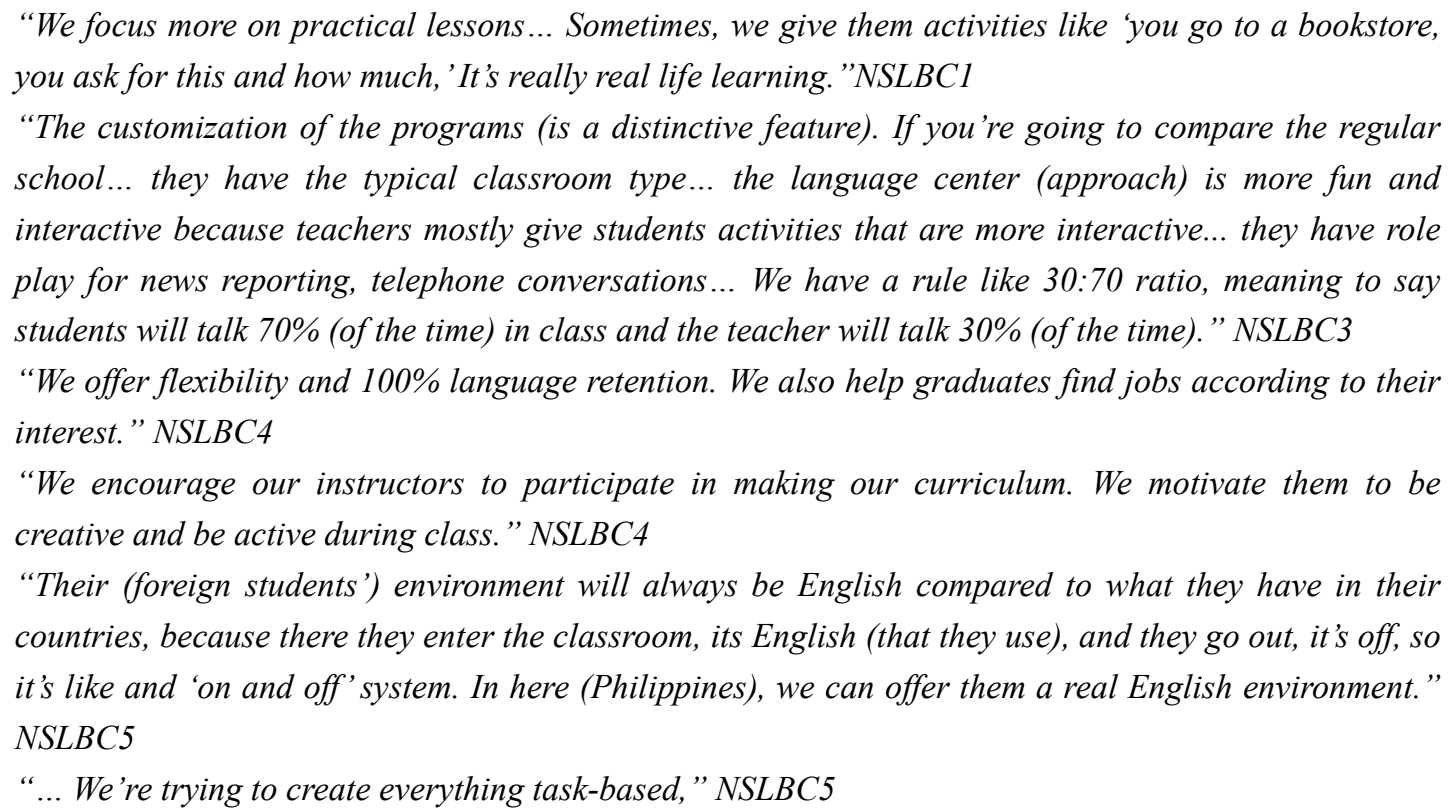

Task-based, non-traditional or non-grammar based, real-life based communication describe the approaches that these LCs abide to when it asked about their program features. It is important to note how they are highlighted against traditional classroom teaching. Perhaps this was done to emphasize the need for language learning outside school. They target compensatory language teaching, that is, although they are note replacing formal schooling, they can provide what clients cannot get and need more from outside school language centers.

\subsection{How to Handle: Management Practices}

Part of understanding the dynamics of language centers is to know how the management is able to handle effectively all the activities going in within the organization to reach their planned goals. The findings in this part of the paper have been divided into the following: Administrative Roles, Instructional Management, Human Resource Management, Management Concerns, and Company Policies.

\subsubsection{Administrative Roles}

It has been found through interviews and documents provided by the LCs that they follow and organized structure. A typical organizational structure can be seen in Diagram 2 . 


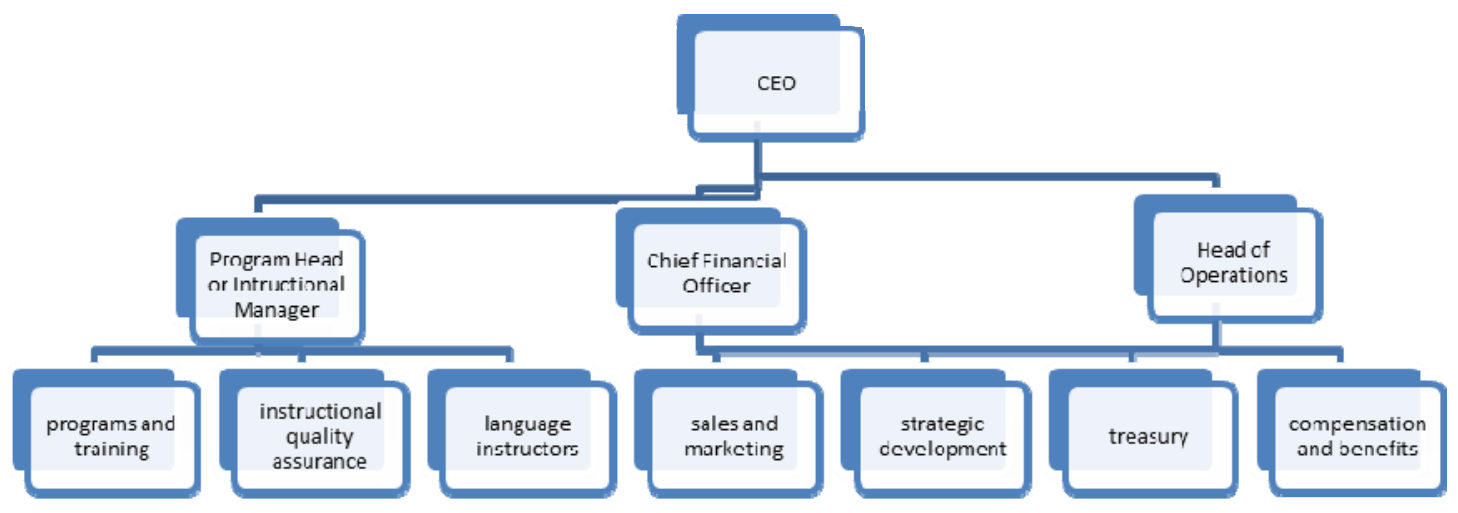

Diagram 2. Typical Organizational Structure

Note: The diagram does not entirely represent all LC's involved in the study. Some components may be present in some structures and not present in others. Also, there may be components in other structures not in the diagram. The diagram represents only what can typically found among them.

\subsubsection{Instructional Management}

Due to differences in hiring status (full-time and part-time) and flexibility of the programs, it is necessary to know teacher involvement in program planning and implementation. The following table shows teacher role and participation.

Table 11. Teacher Role and Participation

"There is a bit of liberty (when it comes to teaching), but we still have to stick to (LC teaching philosophy). For example, the teacher is very strict in her orientation in regular school, that particular teacher had to adjust.” NSLBC1

"We always believe that learning should be fun. (But) Different teachers have their different teaching attacks... That's why we ask them to do teaching demo (demonstration) first. That way we can give them ... the limitations. Although 'yes you can do this, you can do that' but we set rules as well." NSLBC2

"Our teachers actually have the option. Sometimes, we let them do the freestyle teaching but we always make sure that they have to follow the curriculum, because every program we have our course guide that the teacher should follow." NSLBC3

“We encourage our instructors in making our curriculum.” NSLBC4

"(Teachers ) can be involved in the planning. The teachers are part of the company. At the same time, it empowers your teachers which would yield to better results." NSLBC5

It can be seen from the interview quotations that although some LC Management are giving 
their teachers a certain degree of freedom in choosing classroom activities, they have to follow certain company philosophies and policies. In some cases, LCs emphasize the need to create a non-authoritarian classroom, fun and stress-free learning and assign task-based activities. Also, some LCs encourage teacher participation in planning the curriculum as well, and not just in implementation.

Another LC practice discussed in the interviews is the learning evaluation process. The following table describes how LCs ensure quality education through effective evaluation practices.

Table 12. Learning Evaluation Processes

\footnotetext{
"We have a feedback system. We give out evaluation forms to the students and teachers We also have regular meeting as faculty for concerns. " NSLBC1

“..we have the activity logs, for example, for intensive grammar and speaking, because we have the long term and short term programs. It's more important for the long term classes because we want to make sure that we monitor everything especially the progress of the students. That its (is why its) very important that the teacher must log in the topics and activities everyday." NSLBC3

"We have this final evaluation at the end of the class... Actually, there is a pre and post test evaluation for the students... So after the evaluation, say for example, the teacher see if there are improvements or not - that's the time when the teacher have to make a suggestion like extend another twenty hours... ”NSLBC3

"We ensure quality by having international qualification of programs for each language being taught here... We have quality managers for each language and evaluation coming from students. The paramount thing that we address is the quality of our teaching and the learning experience of the students. We monitor student's progress and teaching efficiency with defined science of metrics... "NSLBC4
}

Evaluation of learning is done in various ways from formal to informal approaches and quantitative to qualitative forms. While some LCs conduct informal survey among students eliciting information about student performance, others have come up with more rigorous process like monthly and quarterly evaluation through observation and one even mentioned applying for international qualification although it has not been explained how this is done. Qualitative reports are accomplished through the use of activity logs and progress reports. In one LC observed, the instructor prepares qualitative assessment for the students per skill. However, some LCs opts to conduct quantitative assessments like pre and post test and formal survey about teacher performance.

\subsubsection{Human Resource Management}

The ability to manage human resource is one of the most important tasks of a company. In terms of teacher recruitment, the following processes are being implemented. 
Table 12. Teacher Recruitment Process

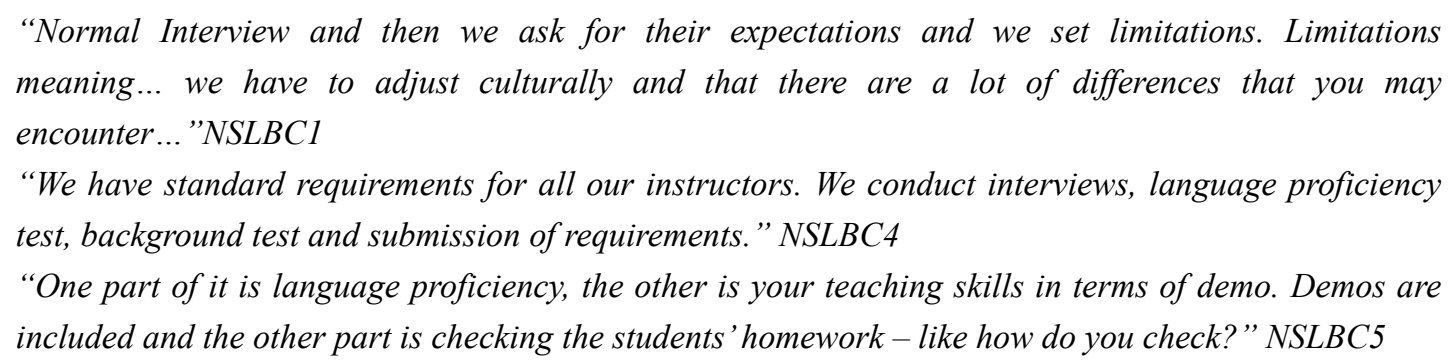

All language centers interviewed conduct teaching demonstration and interview with management, but not all administer language proficiency tests. The hiring process in language centers can be described as standard or general procedure done in other companies and institutions. Only one unlikely activity has been observed, which is the checking of students' activities or papers.

LC's follow two different modes of employment: full time and part-time modes. One characteristic of LC's different from regular schools is that student enrollment is unpredictable; therefore, there are peak and off-peak seasons for them. Part-time hiring is a strategy they used to address problems on the erratic enrollment. However, some LC's are able to provide regular employment for teachers. Advantages of regularization include positive motivation among employees. In some interviews, it was mentioned that during off peak seasons, regular teachers are given tasks related to curriculum and instructional planning. It was claimed that regular status empowers them and encourages them to perform better.

Administrative staff is hired on a regular basis, as they are the ones who oversee the operations within a branch or office. Since LC's maintain a small structure, employees are encouraged to be involved in the planning processes, implementation of policies, problem solving and other important institutional goals significantly more them employees from wider organizations. Teamwork is also highly essential where number of employees is limited. This set-up can results in positive motivation for some teachers and staff.

\subsubsection{Management Concerns}

In answering the question as to how they handle activities within the organization, it was also discussed what usual problems or challenges arise in these language centers. The following statements show challenges in managing LCs: 


\section{Table 13: Management Concerns}

"Miscommunication of staff, cultural differences and strategic scheduling are concerns." NSLBC1

"Unlike in a normal school they can estimate... students, here you cannot predict if they (students) will come in today, tomorrow and that they will like to start immediately." NSLBC1

"If they (students) don't like the teacher... if there's something wrong like... the teacher is not doing good... the teacher always comes in late (that's a problem)." NSLBC2

"As I mentioned earlier we have different types of students. Aside from scheduling, it's very important that you maintain credibility when it comes to students." NSLBC3

"In our diversified environment, we manage more than a hundred instructors at the middle level, and thus we maintain a culture o excellence, ensuring that everybody performs at their optimum and work towards a single vision even though they come from different backgrounds and teachings." NSLBC4

As discussed earlier, searching for appropriate human resource is a very important concern. However, the erratic nature of the enrollment in LC's should also be considered by the management. Other concerns and challenges of management in LC's are summarized into the following:

(1) Carefully plan resources to ensure that they are enough and available whenever there is a demand (through effective scheduling and division of tasks)

(2) Ensure student- teacher compatibility (a concern not observed in regular schools)

(3) Resolve conflicts arising from cultural differences or prevent them from happening (since some students are coming from varying backgrounds, nationalities and religions)

(4) Prevent teacher or student piracy from happening (when teacher or student negotiates to arrange teaching activity outside the company or beyond the control of the company)

\subsubsection{Policies}

Policies in language centers are implemented to carryout tasks much more effectively. The policies mentioned during the interviews can be categorized into three (3) groups according to aspect targeted for development: INDIVIDUAL - policies pertaining to ethics, ENVIRONMENT - policies on promoting a well-maintained learning environment, and COMMUNITY - partnerships and affiliation with external community.

Policies pertaining to ethics and, hence, towards the improvement of individual qualities among members of the organization include establishing professional relationship among colleagues, teachers and students, staff and students and among students. Professionalism also includes positive behavior, constant communication, attendance and proper dress code.

Table 14. Policies pertaining to ethics 
"Our policy is simple and constant communication... the advantage of having small center is that you have the opportunities to talk with each other." NSLBC1

"During orientations, we talk to students about... it's not allowed to offer teachers (and arrange) private tutorials. "NSLBC2

"For cancellation of classes, I would advise them to at least inform us the day before, or 24 hours before the class, because if you're going to inform us within that day, we are going to decut some hours from your time because mostly students are her. So we have to pay for their transportation. "NSLBC3

"The XXXX is open to everybody, and we are strongly guided by our principle of diversity and thus we don't subdivide our clientele based on social status, gender, religion or age. We believe that education should be open to everyone." NSLBC4

Policies in language centers are implemented to carryout tasks much more effectively. The policies mentioned during the interviews can be categorized into three (3) groups according to aspect targeted for development: INDIVIDUAL - policies pertaining to ethics, ENVIRONMENT - policies on promoting a well-maintained learning environment, and COMMUNITY - partnerships and affiliation with external community.

Policies pertaining to ethics and, hence, towards the improvement of individual qualities among members of the organization include establishing professional relationship among colleagues, teachers and students, staff and students and among students. Professionalism also includes positive behavior, constant communication, attendance and proper dress code.

Table 15. Policies on promoting a well-maintained learning environment

“ The XXXX implements a strict policy on the acquisition, utilization, and maintenance of company resources. Our company guides our employees in that process. Furthermore, we are strongly a green company where we promote the use of technology to minimize environmental ... and promote a greener world.” NSLBC4

"Since this is just a small school, in terms taking care of the facility, we also help... We also help in management of the facilities... We do the inventory yearly, and then we do have rules for our students... we do enforce certain policies whenever it comes to the point that they(students) have to replace it (broken facilities)." NSLBC4

Third are the policies related to partnerships and affiliations with external communities. The following statements show the importance of this kind of policy in language centers. 
Table 15. Policies on partnerships and affiliations

"Like I mentioned earlier, our goal is to aid education to employment. That's why we are asking, catering or getting partnerships with different companies. That way, after students graduate from our institute, we can offer them something. " NSLBC2

"When students know you're tied up with XXXX, they don't hesitate to enroll with you. Sometimes students think there is no credibility if there is no partnership. ” NSLBC3

"We're partnering with XXXX, because we have students who take the IELTS, and they greatly assist us in knowing how we could further help our students for them to get their desired scores... Also, another company send students who would like to study here in the Philippines." NSLBC5

Partnerships and affiliation with external communities are also considered important. First, affiliations with other companies can give LCs opportunity for marketing, promotions and recruitment. For instance, some of the LCs collaborate with BPO industries for them to provide English language training to employees or applicants. In another instance, a LC whose clients are mostly Taiwanese students is in partnership with a company who is doing the recruitment in Taiwan and at the same time does the liaison tasks once students are in the country. The LC only had to handle language instruction. Second, partnerships and affiliations help LCs acquire additional resources and materials for teaching. In some instances, partner organizations provide teacher trainings as well. Lastly, LCs find the need to seek the accreditation of government agencies and other educational organizations for company promotional purposes.

\section{Discussion}

\subsection{WHAT TO HARNESS: Purposes and Goals of Language Centers}

Purpose in this research refers to the reason/s for which language centers exist which may be manifested in their philosophy, mission and objectives as a learning institution. These reasons may be internally or externally initiated. According to Doherty (1994), "A satisfactory theory of education should address the teaching/learning processes as central to the mission of the institution, and it should bring to bear on these processes tools for improvement." In knowing the purpose an educational institution, one needs to know the mission and philosophy as well.

It has been discussed how LC's purposes can be divided into three categories: perceived, initial purpose and incidental purpose. Initial and perceived purposes are internally initiated, which refer to ones determined by the institution itself and which they are aware of, while incidental purpose is externally-initiated, which refer to incidental roles that they play in the larger community or society.

Perceived purposes are carefully and thoughtfully formulated purposes highlighted their statement of mission, vision and/or objective. Statements are similar to school-based objectives when they mostly discuss the proliferation of quality education particularly in 
communication using English or another language. These institutional objectives are important since they can serve as a guideline to work ethics shaping staff and students' perspectives to teaching and learning. According to Everard, Morris and Wilson (2004), purpose gives organizations direction and that, “....all organizations, including educational ones, should be actively managed against goals, in other words, not only should there be a clear sense of direction in which the organization is being steered but also markers whereby we can assess progress." (p.143).

Data collected from the interview showed that all language centers agree on the same purpose of teaching effective communication in English and some of them even in other languages. The perceived purposes that are geared towards language education can be summarized into the following:

(1) Teach English language to foreigners whose English is not their native language or second language

(2) Teach English language to local students who need additional skills in the target language to increase employment potential

(3) Teach foreign language to local students to increase employment potential or who are required to speak target language to pursue a present job

(4) Teach foreign language, usually Filipino or Tagalog, to foreigners who would like to do business in the country

Another emerging perceived purpose is one mentioning the cultural awareness, exchange and understanding. These LCs believe that through learning language and intermingling of people from different nations such learning and merging of cultures can also exist. This is understandable since foreigners, who come to the country, first learn about the country's culture from first-hand information they acquire in their language centers. At the same time, the language center environment can also be the first to provide them opportunities to talk about their culture outside their own native environment. Thus, LC's have this vast potential for fostering cultural exchange.

While these LC's are aware of their profit-earning nature, they still believe in the importance of incorporating sincere educational goals as mentioned in their institutional objectives and statement of mission and vision. While it can be said that having these statements is part of their promotional objectives, it can also be assumed that having clear philosophy and objectives that can be shared in public is a good strategy in marketing their services because they can project and impression of trustworthiness, credibility and reliability. Company image and reputation are considered as an organization's intangible resources (Everard, Morris \& Wilson, 2004).

It was also found out that language centers exist as a phenomenon because of the important role it is playing in the present society. To give light to this finding, it is now imperative to discuss the other externally-initiated purposes of LC's which refer to incidental ones, and which only came to light after analyzing data from this study.

First, the widespread phenomenon of LCs in the country is dramatically increasing its 
reputation as a global English teacher. It has been mentioned earlier that some related articles have mentioned that a significant number of foreign students are coming in the country to acquire English education, primarily because it is 'cheaper' to acquire it in the Philippines compared to other countries. Interview data revealed that there are more reasons why foreigners choose the Philippines. The following are reasons usually mentioned in the interviews:

(1) Less stressful learning environment - Filipino teachers are seen to be more patient and less-intimidating especially by Asian students whose English is not their native or second language.

(2) Neutral accent - Philippine English accent (syllable-timed) is more intelligible for EFL (English as Foreign Language) speakers who find native (American) accent to fast (stress-timed).

(3) Second language environment in the Philippines provide foreign students authentic environment for learning English because it is able to provide cross-cultural communication opportunities and authentic reading materials which cannot be provided by their EFL environment

These reasons as seen by foreign students coming to the country for English education are shaping the reputation of our country globally as one of leading countries in terms of English education. This is a reputation which impact cannot be denied since English is becoming more influential in trade and commerce, and that the ability to speak in the language can greatly contribute to economic performance (Global English, 2013).

Second, its proliferation as a form of shadow education which according to Baker (2001), is an important global phenomenon that "represents a deeper theoretical issue concerning the incorporation of schooling into the structure of modern societies throughout the world". This role of language centers can be seen as compensatory for it does not really intend to replace formal learning but compensate for whatever it lacks and provide learning opportunities that students cannot acquire in the case of graduates did not acquire from regular schools. In the case of language center, for instance, students whole enroll aim to acquire additional skills in communication or practice accent neutralization for a job requirement. These skills were not deemed as important (by the students) when they were enrolled in basic education. In other words, the need only presented itself later after formal schooling. In some other instances, foreigners coming to the country and who are still enrolled in basic education, aim to practice English conversational based on the belief that a second language environment can help them improve their English.

Lastly, language centers have a very important role in providing more employment within the country and even abroad. These can be seen in two ways: one is that influx of foreigners in the country to acquire English education is increasing employment opportunities for Filipinos who can teach the language; on the other hand, the services provided by language centers equip local students the communication skills that they need to increase their employment potential whether in the country or abroad. It has been mentioned several times in the interviews that students enroll in a program to enhance English language communication 
skills or learn a foreign language because it is a primary requirement for employment abroad. Also, call center or Business Processing Outsourcing (BPO) applicants need English training for accent neutralization and grammar for them to be fully hired in a company.

The initial, perceived and even incidental purposes discussed reveal the educational, cultural and economic contributions of language centers in the country. This only reveals the important phenomenon that needs further attention.

\subsection{WHAT TO HIGHLIGHT: Programs and Their Features}

In the study of instructional management and theories, it has been known that effective learning is largely based on effective teaching methodologies that are shown in the kind of strategies used in the classroom. According to Gagne et al. (1974), Instruction is defined as "a set of events embedded in purposeful activities that facilitate learning." The effectiveness of instruction is based on careful planning. An instructional system, on the other hand, is "defined as an arrangement and procedures used to facilitate learning. Language centers offer programs that they think will help them achieve their purpose.

Baker et al. (2001) mentioned that outside school activities are actually structured and organized similar to school-like approaches. Since they are offering courses that are given outside a regular school environment, they still tend to mimic school-like approaches and activities, but there are certain differences in the design, approaches and teaching methodologies.

It has been discussed earlier that language centers in the Philippines cater to both foreign and local students. Mostly, foreign students acquire LC's services to learn English language either to pursue higher education, prepare themselves for future jobs or start a business in the country. On the other hand, local students need additional English courses to enhance their proficiency in the language to increase their employment potential whether in the country or abroad. In some instances, local students also want to pursue learning a foreign language as a requirement for an overseas job.

Based on these demands, language centers have offered programs on English as Second Language and Foreign Languages. To address the needs of the industry, some also offer courses on Business English Proficiency and Call Center training programs.

It has also been observed that although there are similarities of curriculum with regular schools, there are also obvious differences; otherwise, students both local and foreign who have taken up English subjects in their regular schools in elementary and high school education will not see the need to acquire their services.

\subsubsection{Deregulated Curriculum}

One important feature that has to be highlighted here is that curriculum and program offerings in LC's are not regulated by any outside agency or organization. Teaching and curriculum in regular schools follow prescribed subjects by a government agency in education; timetable is even prescribed as well as contents to be taught. In LC's, curriculum is dictated by other factors such as (1) demands and needs of the consumers, and (2) 
availability of teaching resources.

Unlike a prescribed curriculum, the LC programs have been designed according to pressing demands available in the society. In recent decades, employability has set higher standards. While all it takes in the past are knowledge and/or skills appropriate to a job, employers in the $21^{\text {st }}$ century has been looking for other pertinent characteristics in their applicants. According to a survey conducted by National Association of Colleges and Employees (NACE), some of the most important skills are related to communication and language skills such as ability to communicate verbally with people inside and outside the organization, obtain and process information, create and edit written reports and sell (products) and influence others (Adams, 2013). This phenomenon led to graduates continuously finding ways to improve their employability. Furthermore, it also happened that most job opportunities today are coming from Business Processing Outsourcing which requires a certain level of proficiency in speaking the English language. However, the BPO style of English has not been the focus of English classes offered in basic education. Consequently, graduate skills and industry expectations are having a mismatch.

LCs has been able to address the issue of raising employability rate of Filipinos since they are able to create or adjust their program offerings based on the demands present in the society. In some instances, LCs also promote education-to-employment opportunities as an additional advantage of their services, and which is rarely given by a regular school program.

Another distinctive feature of LCs is their ability to provide services in preparation for international standardized English proficiency exams such as IELTS and TOEFL. These tests are usually taken to increase employment potential.

Since there are certain needs, whether individual or societal, that regular schooling cannot address nor have foreseen, language centers have seen the need to provide programs that they think will address such demands. Driven by economic needs, and the desire to improve oneself to adapt to the changing demands of the society, students will continuously seek for these programs that they think will advance them in terms of communication skills, interpersonal skills and overall employability.

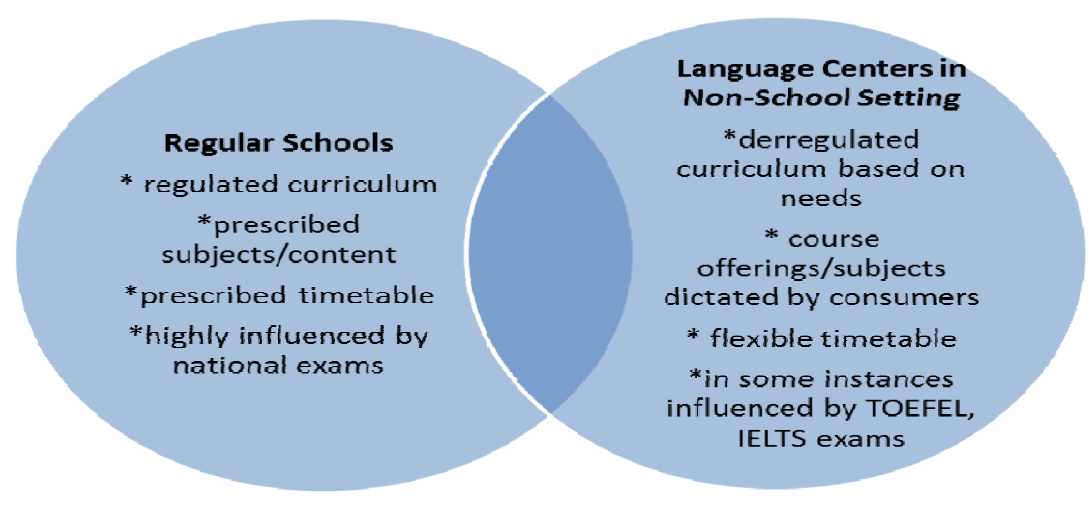

Diagram 3. Agents of Language Education 


\subsubsection{Individualized Learning}

Another emerging feature of LC's is that their curriculum, although preset, can be flexible according to an individual learner's needs All LC's interviewed in the study offer diagnostic tests at the beginning of the learning process to determine proficiency level and also identify the lessons and skills appropriate for the particular students. Also, students are interviewed about their reasons for enrolling to establish the needs and be able to address them in the learning process.

Since learners in the context of LC's are also considered as clients, they get additional benefits and freedom to choose schedule most convenient for them, an advantage that students in regular schools do not have. In some other instances, students can even ask the management to change teachers or instructors if they think the present one is not effective.

According to Everard, Wilson and Morris (2004), "It is increasingly realized that different individuals have different needs, as regards not only curriculum content but also mode of delivery, depending on their preferred learning styles and aptitude." (p.177). It is because of these reasons: flexibility and ability to adapt to learners' needs and significant consideration to their time and even individual learning styles that students continue to patronize language centers despite their previous education and even current education in regular schools.

\subsubsection{Compensatory Language Teaching}

In the era of pedagogical transformation in language teaching, there has been a great shift from grammar-based teaching to a more communicative type of language teaching (Richards, 2006). There has been a massive campaign in teaching language in this approach and several researches have even been conducted about it. However, not all regular schools have totally revamped traditional grammar teaching style. Some teachers still have the tendency to return to a much grammar-focused lesson. The reason for this is that performance of students is still tested through an aptitude type of test consisting of grammar, vocabulary and sentence syntax items that are isolated from a communicative situation. Hence, teachers teach the way students are going to be tested in a prescribed institutional or national government exam.

One outstanding feature of programs offered in language centers that has been repeatedly observed in this research is flexibility. This feature can also be related to language center's ability to easily adopt new teaching styles and use them to create their instructional philosophy. During the interviews, all language centers claimed that they adhere to a student-centered learning in which teachers are considered as mere facilitators of class activities and students participate more in the discussion and completion of tasks. Also, it has been repeatedly mentioned in many interviews that they make use of a more communicative type of language teaching approach. As much as possible, classroom activities are task-based and class management non-authoritarian. Task-based learning has been argued as an effective method in teaching English as foreign language as it increases students' motivation to learn (Ruso, 2007). To adopt a task-based approach is quite sensible since students who engage themselves in real-life communicative activities see the sense of what they are doing and understand the reason for learning. 
The reasons why LCs can easily adopt a communicative approach are that, first, they are not limited by a prescribed or national examination, and second, the controlled class size makes it easier to implement such kind of learning. In this way, it can be seen how language centers are able to compensate for what regular schools cannot provide due to limited resources. However, probably the most influential reason why students see the importance of enrolling themselves in LC programs is their intrinsic motivation to learn and improve themselves in terms of communications skills because of the awareness that they are important in advancing themselves in the society.

\subsection{HOW TO HANDLE: Management Practices and Policies}

Language centers are functioning through an effective management and organizational structure that allows them to perform their tasks like any other school or profit-earning company.

The purpose of management is to set directions and objectives, plan how these goals will be achieved, organize available resources, control processes by measuring achievement against plan, and set organizational standards (Everard, Morris \& Wilson, 2004).

\subsubsection{The LC Difference}

The difference of LCs to Regular schools in terms of instructional management:

(1) Smaller class sizes are observed: one- on- one (teacher-student) tutorial type or small group of not more than 5 .

(2) LC administrators claim that their teaching methodologies include more interactive, task-based and real-life based activities.

(3) LC administrators claim that LC environment is 'less-stressful'.

(4) It has been observed in class observations that teachers are merely facilitators of student activities.

Expectedly, a smaller class size is considered to be advantageous in the learning process. The less students share in the pie of time, the more opportunities each individual receive in expressing his/her ideas, practice certain language skills, and participate in any activity. Moreover, affective filter is lower where learning takes place in a non-restrictive environment which may probably the reason why LC administrators are claiming their centers to be less stressful or stress-free. According to Krashen (1998) in his affective filter hypothesis, usually learners with good motivation and low anxiety learning environment perform better in language acquisition. It can also be assumed that the convenience in terms of choosing time schedule and consideration of their learning styles contribute to lowering anxiety of students in the learning process.

Another emerging term in the interviews is the use of task-based and communicative approaches in classroom activities. It has already been discussed under programs, how LCs has been able to provide more communicative and real-life based tasks in the classroom in which students see the sense of what they are doing. A communicative vs. a grammar-based style of teaching has been chosen because most clients enrolled are geared towards 
employment. Unless clients request for an advanced grammar training, they are most likely to receive training on speaking, listening and even reading and writing. In other words, lessons and activities are designed according to the client's end goal. If a client needs to learn language for business purposes, then he or she is given training on how to handle business transactions and other business communicative situations. On the other hand, if the client is aiming for a position in the BPO industry, he or she is given training on accent neutralization.

\subsubsection{Client-based Approach}

Another emerging characteristic of instructional management in LCs is their treatment of students as clients. They have certain benefits when it comes to deciding on schedule most convenient to them, identifying end goal of learning, and even requesting for a change of teacher if they find the current one to be ineffective. These are choices not typically available to students in regular schools.

\subsubsection{Meeting Demands and Facing Challenges}

"The key to effective management is the ability to get results from other people, through other people and in conjunction with other people." (Everard, Morris \& Wilson, 2004, p.34). Another basis of an organization's effectiveness is determined by its ability to motivate people to perform well in their assigned tasks. Since language centers are relatively small companies, it was not difficult to monitor tasks and activities going on in the organization. The positive effect of a small company is how it motivates its employees to work harder since they see directly the results of their efforts. However, due to the unpredictable nature of LC business, there are important concerns that they have to address regarding resources.

As observed in the findings in this research, managing resources, especially human resources, is one of the most important challenges of the management in language centers. Due to the unpredictability of enrollees, they have to think and implement strategies that would help them address the problem of teacher-student ratio mismatch. The common strategies that emerged from the findings were either they establish strong partnerships with a company doing recruitment tasks, or direct partnerships with BPO industries in which they can regularly conduct Call Center English or Business English trainings and seminars. Another way to solve this problem is to hire teachers using the contractual mode of employment. For some other companies, strategic scheduling is a way to solve such dilemma.

Management concerns vary depending on the kind of company set-up, types of clients and programs offered. For instance, in one language center where most clients are Turkish, respect for culture and religious practices is a very important concern that has to be addressed appropriately by management and teachers. In another company in which clients are mostly Taiwanese high school students, the management's concern is about their students' welfare while in a foreign country.

\subsubsection{Creating and Implementing Policies}

Policies are important to language centers as they help in smooth flow of operations happening in their organizations. As described in the findings, policies target three areas 
which are policies pertaining to ethics and in a way target the development of values among individuals and maintenance of positive and professional behavior among all members of the organization. This is important since it is understood that these positive and behavior can result in a more productive workforce which is advantageous for company itself in furthering its goals. Credibility and company reputation are also matters that the are concerned about that is why they implement these policies. Moreover, policies promoting a well-maintained environment were also seen as important to language centers. Physical facilities and structure is essential to be able to conduct the activities of the organization. Any problem recurring from lack or broken facility can also affect the other activities going on within it. It is probably for this reason that these policies are being implemented. Lastly, policies relating to links to external communities are important are able to help them in terms of promotions, client recruitment and resource acquisition.

\section{Conclusions}

The following conclusions can be made based on the findings of this study:

(1) The purposes of LC's can be divided into three categories: perceived, initial and incidental. The perceived purposes which can be seen from their institutional goal to extend language education to both local and foreign students. The initial purpose refers to goals as business organizations, while most LCs objective is primarily profit-driven, it can be inferred from their stated institutional philosophies their important role as agents of language education. The externally-initiated goals are incident roles they play in the society. Their role as agents of language education has elevated the image of the country as a global English teacher. Moreover, language centers have incidentally also become a potential environment for cultural understanding, exchange and learning, and potential contributors to the country's economy by addressing issues in employment.

(2) Programs offered in language centers are decided based on demands in the society and availablity of resources.

(3) Language center programs have distinct features that made clients patronize them. Some of these important features are deregulated and flexible curriculum, individualized learning, and compensatory language education. Language programs have also been designed based on perceived purposes of the institution.

(4) The effectiveness of LCs in performing their tasks is also based on effective management of instruction, human resources, finances and facilities and implementation of important policies.

(5) Distinct features of instructional management include convenient learning schedules, consideration to teacher-student compatibility and learning preferences, smaller class sizes catering to more learning opportunities and an anxiety-free environment. Management style is client-based which means highly considering convenience, welfare and preferences of clients. 


\section{References}

Baker, D. et al. (2001). Worldwide shadow education: Outside school learning, institutional quality of schooling, and cross-national mathematics achievement. Educational evaluation and policy analysis, 23 (1), 1-17.

Kugler, M. R. (2001). Alter school programs are making a difference. NASSP Bulletin, 85 (626), 4-11.

Bush, T., Bell, L., Bolam, R., Glatter, R., Ribbins, P. (Eds.) (1999). Educational Management: Redefining theory, policy and practice. London: PCP.

Doherty, G.D. (Ed.) (1994). Developing Quality Systems in Education. New York: Routledge.

Everard, K. B. (2004). Effective school management. London: Paul Chapman Publishing.

Gagne, R. M. \& Briggs, L.J. (1974). Principles of intstructional design. New York: Holt, Rinehart and Winston.

Kachru, B. (1992). The other tongue: English across cultures $\left(2^{\text {nd }}\right.$ ed.). University of Illinois Press.

McGeown, K. (November 2012). The Philippines: The world's biggest english teacher. BBC News. Retrieved from http://www.bbc.com/news/business-20066890

McKay, S. L. (2002). Teaching english as an international language. Oxford University Press.

Richards, J. C. (2006). Communicative language teaching today. Cambridge University Press.

Ruso, N. (2007). The influence of task based learning in EFL classrooms. Asian EFL Journal, 18. http://www.asian-efl-journal.com/pta_February_2007_tr.pdf

Rutledge, S., Cohen-Vogel L. \& Osborne-Lampkin, L. (2012). Identifying the characteristics of effective high schools: Report from year one of the National Center on Scaling Up Effective Schools. Vanderbilt Peabody College.

Young, J. et al. (2011). High schools that work: Program description, literature review, and research findings. Princeton, New Jersey: ETS.

Global English Business English Index Reveals Skills Shortage and Unequal Odds for International Business Success in 2012. (April 2012). Retrieved from Global English website http://www.globalenglish.com/whoweare/newsroom/press_releases/757

\section{Copyright Disclaimer}

Copyright for this article is retained by the author(s), with first publication rights granted to the journal.

This is an open-access article distributed under the terms and conditions of the Creative Commons Attribution license (http://creativecommons.org/licenses/by/3.0/). 